\title{
Pozitif Psikoloji Akımının Zihinsel Yetersizliği Olan Çocuğa Sahip Anneler Örnekleminde İncelenmesi*
}

\author{
An Investigation of the Positive Psychology Current in the Sample of Mothers with Children \\ with Intellectual Disabilities
}

\section{Erdi KULBAŞ ${ }^{[1]}$ Nilüfer ÖZABACI[2]}

Başvuru Tarihi:04 Eylül 2021

Zihinsel yetersizliğin her seviyesinde bireyler bir öğretici tarafından eğitime, bir yetişkin tarafından fiziksel veya duygusal desteğe ihtiyaç duyarlar. Zihinsel yetersizliği olan bireylerin en önemli destek kaynağı ise anneleridir. Ancak büyük umutlarla ve hayallerle dünyaya gelen çocuklarının zihinsel yetersizlik tanısı alması her anne için birçok zorluğu beraberinde getirir. Bu anlamda öncelikle zihinsel yetersizliği olan bireyin annesinin fiziksel, duygusal ve psikolojik olarak sağlıklı olması önem arz etmektedir. Ailelerin ve özellikle annelerin yaşadıkları duygusal süreçten bir an önce çıkıp duruma uyum sağlamaları hem kendileri hem de aileleri için çok önemlidir. Bunun yanında çocuğunun bağımsızlığına yönelik umut geliştirmenin yolu birincil bakım rolü olan annelerin olumlu duygularını ve iyi oluşunu artırmaktan geçmektedir. Araştırmaya konu olacak literatür incelendiğinde bireylerin güçlü özelliklerini ve olumlu yönlerini ele alarak potansiyelini işlevsel bir biçimde kullanmasını hedefleyen pozitif psikoloji akımı, annelerin yaşadıkları psikolojik sürece ilişkin birçok yönden açılamalar sunabilmektedir. Bu anlamda çalışmanın amacı zihinsel yetersizliği olan çocukların annelerinin psikolojik durumlarını pozitif psikoloji akımı çerçevesinde değerlendirmektir. Araştırma sonucuna göre annelerin yaşadıkları psikolojik sürecin pozitif psikoloji akımının çalışma alanlarından psikolojik iyi oluş, öz anlayış, umut ve iyimserlik gibi kavramlarla ilişkili olduğu görülmüştür. Bu anlamda araștırmanın son bölümünde ilgili kavramları konu alan teorik çalışmalar ve kavramlar üzerinde etkililiği kanıtlanmış deneysel programlar sunularak önerilerde bulunulmuştur.

Anahtar Kelimeler: pozitif psikoloji, zihinsel yetersizlik, psikolojik iyi oluş, öz anlayış, umut, iyimserlik

Received Date:04 September 2021

Individuals at all levels of intellectual disability need training by a teacher and physical or emotional support by an adult. The most important source of support for individuals with intellectual disability is their mothers. However, the diagnosis of intellectual disability for children born with great hopes and dreams brings many difficulties for every mother. In this sense, it is important that the mother of the individual with mental disability is physically, emotionally and psychologically healthy. It is very important for both themselves and their families that families, and especially mothers, get out of the emotional process and adapt to the situation as soon as possible. In addition, the way to develop hope for the independence of their child is to increase the positive emotions and well-being of mothers who have a primary care role. When the literature that will be the subject of the research is examined, the positive psychology movement, which aims to use the potential of individuals in a functional way by addressing their strong characteristics and positive aspects, can provide explanations from many aspects of the psychological process experienced by mothers. In this sense, the aim of the study is to evaluate the psychological state of mothers of children with intellectual disability within the framework of positive psychology. According to the results of the research, it has been seen that the psychological process experienced by the mothers is related to concepts such as psychological well-being, self-understanding, hope and optimism, which are among the fields of study of the positive psychology current. In this sense, in the last part of the research, theoretical studies on related concepts and experimental programs with proven effectiveness on the concepts were presented and suggestions were made.

Keywords: positive psychology, mental disability, psychological well-being, self-compassion, hope, optimism

Kulbaş, E., \& Özabacı, N. (2021). Pozitif psikoloji akımının zihinsel yetersizliği olan çocuğa sahip anneler örnekleminde incelenmesi. Humanistic Perspective, 3 (3), 676-695. https://doi.org/10.47793/hp.991219

* Bu makale birinci yazarın ikinci yazar danışmanlığındaki doktora tezinden türetilmiştir.

[1] Dr. | Milli Eğitim Bakanlı̆̆ | İstanbul | Türkiye | ORCID: 0000-0001-6104-2851| erdikulbas@hotmail.com

[2] Prof. Dr. | Yeditepe Üniversitesi | Rehberlik ve Psikolojik Danışmanlık | İstanbul | Türkiye | ORCID: 0000-0001-6237-1921 


\section{GíRiş}

$\mathrm{Z}$

ihinsel yetersizliği olan bir çocuğun doğumu veya tanılanması, aile için önemli ve benzersiz bir sürecin oluşmasını beraberinde getirir. Bir birim olarak aile ve bireysel üyeleri, gelecekle ilgili şok, keder, suçluluk ve belirsizlik duygularıyla başa çıkmak zorunda kalırlar (Gatford, 2007). Anne babalar normal gelişim gösteren çocuğu olan anne babalara göre yaşam kalitesi düşük, depresyonlu ve geleceğe karamsar bakış açısına sahip olma eğilimindedir (Cappe vd., 2011; Johnson vd., 2011). Bu belirtiler, babalardan ziyade annelerde daha yaygındır (Altiere ve Von Kluge, 2009). Ayrıca, çocuğun birincil bakıcısı olan anne, çocuk bakımı becerilerine yönelik suçluluk duygusu, gerginlik ve endişe geliştirme eğilimindedir (Jose vd., 2017; Koydemir ve Tosun, 2009). Bu süreç, ailenin içinde bulunduğu sosyo-kültürel ve gelişimsel bağlamdan güçlü bir şekilde etkilenir, çünkü bu faktörler ailenin engellilik algısını ve bunu durumla başa çıkmak için sahip olduğu kaynakları şekillendirir (Xu, 2007).

Birtakım yetersizlikleri olan bireyin bakımı ile ilgilenen kişiler yaşamış oldukları sıkıntı, endişe ve bilinmezlikler neticesinde umutsuzluk ve depresif ruh hali gibi durumlara yatkın hale gelirler (Atagün vd., 2011). Bunun yanında ebeveynler kendilerine karşı öfke, suçlayıcı davranışlar ve hayal kırıklığı, sosyal izolasyon duyguları, çocuğun toplum içindeki davranışından utanç vb. geliştirme eğilimindedir (Bekhet, Johnson ve Zauszniewski, 2012). Aileler bunun yanında ilişkilerinde önyargı, korku ve reddedilme ile mücadele etmek zorunda kalabilirler (Sarı, Başer ve Turan, 2006). Aileler, çocuklarının kabul edilmediğini, tehdit edici ve itici olarak algılandığını hissedebilirler. Zihinsel yetersizliği olan bir çocuğa ebeveynlik yapmanın artan zorlukları, ebeveynlerin iyi oluşunu etkileyebilir (Crabtree, 2007).

Zihinsel yetersizliğin her seviyesinde bireyler bir öğretici tarafından eğitime, bir yetişkin tarafından fiziksel veya duygusal desteğe ilgiye ihtiyaç duyarlar. Zihinsel yetersizliği olan bireylerin en önemli destekçisi ise anneleridir. Bu anlamda öncelikle zihinsel yetersizliği olan bireyin annesinin fiziksel, duygusal ve psikolojik olarak sağlıklı olması önem arz etmektedir (Vural-Yüzbaşı, 2018). Bu anlamda duygusal olarak sağlıklı olan anneler, duygularını ve davranışlarını kontrol edebilir ve zorluklarla baş edebilir, güçlü ilişkiler kurabilirler (Bekhet, Johnson ve Zauszniewski, 2012). Araştırmalara göre umut ve iyimserlik zihinsel yetersizliği olan çocukların ebeveynleri için önemli koruyucu faktörler olduğu (Kashdan vd., 2002) ve bu faktörlerin ebeveynlik davranışları ile önemli ilişkileri olduğu gösterilmiştir. Bunun yanında ebeveynlerin ilk etapta çocuklarının durumuna neden oldukları için kendilerini mantıksız bir şekilde suçlayıcı (Fernandez ve Arcia, 2004) davranışları öz anlayış düzeylerini sarsmaktadır. Öz anlayışlı bireyler kendine şefkat ve özenle davranarak, acı çekmenin paylaşılan insan deneyiminin bir parçası olduğunu hatırlayıp yaşam zorluklarını başarıyla karşılamak için daha fazla duygusal kaynağa sahip olurlar. Bu nedenle öz-anlayışın, ebeveynlerin otizmli veya zihinsel 
yetersizliği olan bir çocuk yetiştirmenin zorluklarıyla başa çıkma becerisinde rol oynaması muhtemeldir (Neff, 2011). Bu konuda Bögels, Lehtonen ve Restifo (2010), artan öz-anlayışın, otistik çocukların ebeveynleri için farkındalık temelli müdahalelerin etkili olduğu kilit bir mekanizma olabileceğini savunmuştur.

Gelişen ve değişen sosyal yapıya uygun olarak psikoloji akımları da dönemden döneme farklılık gösterip uygun yaklaşımlar çerçevesinde şekillenir (Luthans, 2002). Nispeten yeni bir yaklaşım olan pozitif psikoloji de bu akımlardan biridir. Pozitif psikolojinin bakış açısı sadece hayattaki en kötü şeyleri onarmakla meşgul olmaktan ziyade, yaşamdaki en iyi nitelikleri inşa etmeye yönelik bir değişimi katalize etmektir. Bunun sonucunda ele aldıkları çalışma konuları ile bireylerin iyi oluşlarını artırmak mutlu ve sağlıklı bir yaşam geçirmelerini sağlamak amaçlar arasındadır (Seligman ve Csikszenmihalyi, 2000). Bu çalışmada da zihinsel yetersizliği olan çocuğa sahip olan annelerin yaşadıkları psikolojik sürecin pozitif psikoloji kavramlarından psikolojik iyi oluş, öz anlayış, umut ve iyimserlik kavramları ile ilişkisi ve pozitif psikolojiye dayalı müdahale yöntemleri incelenmiştir.

\section{Pozitif Psikoloji}

İkinci Dünya Savaşıı'ndan önce bireylerin iyilik hallerini artırma, üstün yetenekli bireyleri ortaya çıkarma, rahatsızlıkları iyileştirme gibi konularda çalışmalar yapan psikoloji bilimi İkinci Dünya Savaşı'ndan sonra, büyük ölçüde iyileșmeye adanmış bir bilim haline geldi. İnsan doğasına ilişkin hastalık modelini kullanarak hasarı onarmaya odaklandı. Patolojiye yönelik bu özel ilgi, tamamlanmış bir birey ve gelişen bir topluluk fikrini ihmal etti (Linley, 2009). Nitekim Dünya Sağlık Örgütü sağlık tanımını herhangi bir rahatsızlığa sahip olmayan birey çerçevesinde değil; fiziksel, ruhsal ve sosyal olarak iyilik haline sahip birey olarak ifade etmiștir. Son yllarda ise gerek Dünya Sağlık Örgütü'nün sağlık tanımı gerekse dünya üzerindeki toplumsal yapının değişime uğraması birey temelli yaklaşımların ortaya çıkmasını sağlamıştır. Bu yaklaşımlardan biri de pozitif psikolojidir (Hefferon ve Boniwell, 2014).

Pozitif psikolojinin geçmişi çok eskilere dayandırılabilmesine rağmen bu yaklaşım Martin Seligman tarafından 1998 yılında Amerikan Psikoloji Derneği başkanı olduğu dönemde bilim dünyasına tanıtılmıştır. Seligman'a (2002) göre, pozitif psikoloji sadece hastalığın, zayıflığın ve bozukluğun onarılması değil; ayrıca güçlü özelliklerin ve olumlu yanların da incelenmesidir. Tedavi bir bakıma doğru olanın inşasıdır. Pozitif psikoloji problem odaklı bakış açısından uzaklaşarak bireylerin potansiyellerini ortaya çıkarma ve geliştirme, mutluluk ve iyi oluş seviyelerini artırma gibi olumlu özelliklere odaklanmıştır. $\mathrm{Bu}$ yaklașıma göre bireyin sadece ruhsal rahatsızlığını tedavi etmek değil; onun kişisel güçlerini ortaya çıarmasını ve kullanmasını sağlamak, iyi oluşunu artırmak, mutlu ve dayanıklı bir birey haline gelmesine odaklanmak önceliklidir (Hefferon ve Boniwell, 2014). 
Mutluluğun ve iyi oluşun anlaşılması ve açıklanması ile bunları etkileyen faktörlerin doğru tahmin edilmesi bu yaklaşımda odak noktası olarak ele alınan hususlar arasındadır. Bozuklukların olumsuz belirtilerini dikkate alan bu yaklaşım, temel olarak olumlu bir bakış açısıyla insanların mutluluğunu ve refahını artırmayı amaçlamaktadır. Bu nedenle pozitif psikoloji, geleneksel ve çağdaş psikolojiyi tamamlayan bir alandır (Seligman vd., 2005).

Pozitif psikolojinin çalışma alanı öznel, bireysel ve grup düzeyinde ele alınır. Öznel düzeydeki alanı, pozitif öznel deneyimle ilgilidir: geçmiş açısından esenlik ve tatmin; şimdi akış, neșe, duyusal zevkler ve mutluluk; gelecekle ilgili yapıcı bilişler, iyimserlik, umut ve inanç incelenir. Bireysel düzeyde, cesaret, kişilerarası beceri, şefkat, estetik duyarlılık, azim, bağışlayıcılık, özgünlük, geleceğe dönüklük, yüksek yetenek ve bilgelik gibi olumlu kişisel özelliklerle ilgilenir. Grup düzeyinde ise, vatandaşlık erdemleri, bireyleri daha iyi vatandaşlığa doğru yönlendiren sorumluluk, özen, fedakarlık, nezaket, ılımlılık, hoşgörü ve iş ahlakı gibi kavramlarla ilgilidir (Seligman ve Csikszentmihalyi, 2000).

Görüldüğü üzere pozitif psikolojinin çalışma alanı insanın olumlu özelliklerinin tamamını ele alan bir noktada olduğu için oldukça geniştir. Bu araştırma kapsamında ise zihinsel yetersizliği olan bir çocuğun annesinin psikolojik durumu dikkate alınarak psikolojik iyi oluş, öz anlayış, umut ve iyimserlik kavramları incelenmiştir.

\section{Psikolojik İyi Oluş ve Zihinsel Yetersizliği Olan Çocuğa Sahip Anne}

İyi oluş kavramı literatürde öznel iyi oluş ve psikolojik iyi oluş olarak iki alt başlık içerisinde ele alınmıştır. Öznel iyi oluş, yaşam memnuniyeti, olumlu ve olumsuz duygulanım arasındaki denge ile açıklanmaktadır. Psikolojik iyi oluş ise, yaşamın varoluşsal zorluklarıyla mücadeleyi temel alan kişinin tüm benliği ile gelişimini ifade eden bir kavramdır (Keyes, Shmotkin ve Ryff, 2002).

Ryff (1989), psikolojik iyi oluş konusunda altı boyutta açlklanabilecek bir formülasyon önermiştir. Ryff ve Keyes'e (1995) göre, psikolojik iyi oluşun her bir boyutu bireyin olumlu işlev göstermeye çalışırken karşılaştığı zorlukları tanımlar. Keyes, Shmotkin, ve Ryff'a (2002) göre, insanlar kendi sınırlamalarının (kendini kabul) farkındayken bile kendileri hakkında iyi hissetmeye çalışırlar. Ayrıca, sıcak ve güvene dayalı kişilerarası ilişkiler (başkalarıyla olumlu ilişkiler) geliştirmeye ve çevrelerini kişisel ihtiyaç ve arzuları karşılayacak şekilde şekillendirmeye (çevresel hakimiyet) çalışırlar. Bireyselliği daha geniş bir sosyal bağlamda sürdürürken, insanlar aynı zamanda kendi kaderini tayin etme ve kişisel otorite (özerklik) duygusu ararlar. Yaşamsal olarak, çabalarında ve zorluklarında (yaşam amacı) anlam ararlar. Son olarak, kişinin yeteneklerinden ve kapasitelerinden (kişisel gelişim) en iyi şekilde faydalanmaya çalışması psikolojik iyi oluşun merkezinde yer alır. 
Normal veya tipik gelişim gösteren çocuğu olan ebeveynlere kıyasla, zihinsel yetersizliği olan çocukların ebeveynleri onlardan daha fazla zorlukla karşılaşmaktadır. Bu sorun, onları psikolojik bunalım, zihinsel sağlık sorunları, kötü sağlı, uyum sorunları ve düşük düzeyde psikolojik iyilik haline yatkın hale getirir (Hayat ve Zafar, 2015).

Ebeveynlerin çocuk bakımı sırasındaki stres düzeyi, çocuk bakım işlevlerini ve ebeveynler ile çocuklar arasındaki ilişkiyi etkiler (Mitchell vd., 2018). Problem çözme ve stres yönetimi ile ilgili kişisel yeteneklerden biri psikolojik iyilik halidir. Yüksek oranda stres ve depresyon belirtileri psikolojik iyi oluşu kötü olan kişilerin bir parçasıdır (Desiningrum, 2018). Otizmli çocukların anneleri düşük psikolojik iyi oluşa sahip olma eğilimindedir (Cox vd., 2015). $\mathrm{Bu}$ nedenle annenin başa çıkma stratejisi etkisiz hale gelir. Zihinsel yetersizliği olan çocukların anneleri yaşam kalitesi ve ruh sağlığının iyi olması ile gösterilen psikolojik iyi olma durumunu yaşamaları ile çocuklarının zorlu koşullarına uyum sağlama yeteneklerini geliştirirler (Hsiao, 2016). Bu nedenle anneler için psikolojik olarak iyi olmak önemlidir, çünkü anneler kendilerini iyi hissedebilirlerse çocuklara daha iyi bakım ve eğitim sağlayabilirler (Neff ve Faso, 2015).

\section{Öz Anlayış ve Zihinsel Yetersizliği Olan Çocuğa Sahip Anne}

Farkındalıkla yakından ilişkili bir yapı olan öz-anlayış, son zamanlarda araştırma literatüründe ilgi görmeye başlamış bir kavramdır. Neff (2003), öz-anlayışın birbiriyle etkileşim halinde olan üç bileşenden oluştuğunu öne sürmüştür. Bunlar: öz şefkate karşı öz yargllama, ortak insanlığa karşı izolasyon ve farkındalığa karşı aşırı özdeşleşmedir. Öz şefkat, kişisel eksiklikler için kendine saldırmak ve kendini azarlamak yerine, sıkıntılı zamanlarda nazik, destekleyici ve kendine karşı şefkatli olmayı gerektirir. Ortak insanlık, birinin acısıyla izole hissetmek yerine, tüm insanların hata yaptığını ve yaşamlarında zorluklar yaşadığını kabul etmeyi içerir. Öz-şefkat bağlamında farkındalık, kişinin kendisinin veya yaşamının olumsuz yönlerini ne görmezden gelme ne de derin düşünme, netlik ve denge ile acı veren düşüncelerin ve duyguların farkında olmayı içerir.

Öz anlayış kişinin yaşadığı olumsuz duruma karşı kendisine sevecen bir tutum takınması, yetersizlik ve başarısızlık anında şefkatini kullanarak onu iyileştirmesi olarak ifade edilir (Deniz, Şahin ve Sümer, 2008). Zihinsel yetersizliği olan çocukların annelerinin de bu duruma ilişkin yaşadıkları nihai duygu utanç ve başarısızlık hissidir (Gray, 1993). Mak ve Kwok’a (2010) göre, ebeveynler çocuklarını "kontrol edemedikleri” için çevreleri tarafından eleştirilip kınanabilirler. Durumlarının fiziksel bir belirteci olmadığından, çoğu sadece çocuğun yanlış davrandığını varsayar. Başkalarından gelen yargı, daha etkili bir ebeveyn olmadıkları için genellikle kendi kendini suçlamada içselleștirilir. Ebeveynler, özellikle hangi tedavileri denemeleri gerektiği konusunda başkalarının sürekli tavsiyesiyle, doğru tedavi seçimlerini yapmadığını düşünebilirler (Miller vd., 2012). Ayrıca otizmli çocuğu olan ebeveynler çocukları için yeterince 
tedavi ve eğitim olanağı araştırmadıkları için suçluluk duygusu yaşayabilirler. Bu utanç, suçluluk ve öz yargılama kişiyi stres, depresyon ve anksiyeteye yatkın hale getirir (Mak ve Kwok, 2010).

Öz-anlayış mutluluk, iyimserlik ve yaşam doyumu gibi olumlu psikolojik sonuçlarla da bağlantılıdır (Hollis-Walker ve Colosimo, 2011; Neff, Pisitsungkagarn ve Hseih, 2008). Araştırmalar, öz-anlayışlı olmanın motivasyonun güçlü bir yordayıcısı olduğunu ve bunun da daha fazla algılanan güvene ve daha az başarısızlık korkusuna yol açtığını göstermiştir (Smeets vd., 2014). Öz anlayışlı ebeveynlerin ayrıca çocuklarıyla daha işlevsel ilişkilere sahip oldukları yani etkileşimlerini hayal kırıklığı yaratan veya duygusal olarak kopuk bulmadıkları gözlemlenmiştir (Neff ve Beretvas, 2013). Ebeveynlerin bu durumla başa çıkması açısından önemli bir faktör olarak görülen farkındalık; geniş anlamda, bir açıklık ve merak duruşunu korurken, șimdiki anda dikkatin kendi kendini düzenlemesini ifade eder (Bishop vd., 2004).

Farkındalık temelli müdahalelerin, genel olarak zihinsel yetersizliği olan çocukların ebeveynleri (Myers vd., 2014) ve özellikle otizmli çocukların ebeveynleri arasındaki (Coatsworth vd., 2010) stresi azalttığı gösterilmiştir. Özellikle farkındalık, otistik çocukların ebeveynleri arasında daha iyi olma hali ile de ilişkilendirilmiștir (Conner ve White, 2014). Bu anlamda öz anlayışın ebeveynler için kendilerine duygusal bakım yapmalarına yardımcı olarak daha sağlıklı bir denge oluşturduğu düşünülmektedir.

\section{Umut, İyimserlik ve Zihinsel Yetersizliği Olan Çocuğa Sahip Anne}

Snyder (2002), umudu, kişinin potansiyeli doğrultusunda amaçlar belirlemesi, amaçlara ulaşabilecek yolları belirlemesi ve yaşayacağı engellere ilişkin motivasyon geliştirmesi olarak tanımlamıștır. Umut; bireyi harekete geçiren ve onun geleceğe iyi bakmasını kolaylaştıran, bu anlamda ruhsal iyi oluşu artıran bir düşünce türüdür. Umudu yüksek olan birey daha fazla yaşama amacına sahip, olumsuzluklarla baş edecek gücü elinde barındıran, enerjisi yüksek bir yapıdadır (Tarhan ve Bacanlı, 2015).

Snyder’e (2005) göre, orta düzeyde belirlenen amaçlar kişileri geleceğe ilişkin daha umutlu kılar. Amaçlardan oluşan umut teorisi amaçların gerçekleştirilme düşüncesini de ele alır. Bu düşünsel yapı öncelikle amaca gidecek işlevsel yolları planlama daha sonra kişinin kendisine ve planına yönelik inanç geliştirmesinden geçer. Snyder'in "Pathways" olarak adlandırdığı bu boyut kişinin şu anki durumu ile gelecekte olmak istediği nokta arasındaki konumuna ilişkin yeterlilik algısını ifade eder. Alternatif düşünceler ise amaca giden yollarda karşılaşılan engellere ilişkin pes etmeme motivasyonunu oluşturur ve kişiye yeni yollar sunar. $\mathrm{Bu}$ da umudun geliştirilmesinde devamlılık sağlar (Rand ve Chavens, 2009).

Zihinsel yetersizliği olan çocukları yetiştiren ebeveynler için umut, hedefler ve eylemlilik önemlidir. Bu görevin getirdiği günlük zorlukların üstesinden gelmek, hedeflerin belirlenmesini 
ve hedeflere yönelik çalışmayı gerektirir. Daha büyük bir inanç duygusuna ve hedeflere ulaşmak için daha fazla yola sahip olan ebeveynler, olmayanlara göre daha iyi uyum sağlayabiliyor gibi görünmektedir (Horton ve Wallander, 2001), bu da onların dayanıklılıklarını artırmaktadır.

Scheier ve Carver (1985), iyimserliği, geleceğin olumlu olacağı inancıyla karakterize edilen nispeten istikrarlı bir kişilik özelliği olarak tanımlamıştır. Umut teorisinde olduğu gibi, Scheier ve Carver (1985), tüm insan davranışlarının amaca yönelik olduğunu öne sürmüştür. İyimserlik, bir kişinin hedefe yönelik bu davranışların sonuçlarına ilişkin inançlarıdır ve kişinin, hedeflere ulaşılacağına dair sahip olduğu güven veya sahip olduğu iyimserlikle doğrudan ilgilidir (Carver ve Scheier, 2002). İyimserlik teorilerinin Umut Teorisi ile pek çok benzerliği vardır ve iyimserliğin kavramsal olarak umutla ilişkili olduğu gösterilmiştir. Spesifik olarak, her iki teori de hedeflerin ve sonuçların önemli olduğunu vurgular ve her ikisi de davranışın hedefler tarafından motive edildiği varsayımına dayanır (Snyder, Rand ve Sigmon, 2002). İyimserlik teorileri, umut teorisinden farklı olarak, yolların veya motivasyonel düşüncenin kökenlerini ele almaz, ancak bireylerin beklentilerine odaklanır (Scheier ve Carver, 1985). Kısacası, iyimserlik, kişinin hedeflere ulaşılacağına olan inancını ele alır ve umut, bu hedeflere nasıl ulaşılacağını ele alır ve ayrıca kişiyi bu hedeflere ulaşmaya motive eder. Umut, hedeflere ulaşmak için yollar yaratma yeteneğini ve bu yolları takip etme motivasyonunu içerir; İyimserlik, bu hedeflere ulaşılacağı inancını içerir. Umut daha çok hareket halindeki eylemle, iyimserlik ise geleceğe olan inançla ilgilidir.

Seligman (2002), iyimser insanların olumsuz sonuçlardan kaçınmaya çalıştıkları ve olumlu ve istenen sonuçlara doğru çabaladıkları için iyimserliğin hedefle ilgili olduğunu öne sürmüştür. İyimser insanlar, bu sonuçları sağlayacak eylemlerde bulunabileceklerine inanırlar. Hedefe ulaşma yolunda engeller veya tıkanıklıklar meydana geldiğinde, iyimserliği yüksek olan bu bireyler, bu durumlara yaklaşma konusunda daha az sıkıntı ve daha fazla güven yaşama eğilimindedir ve engellere rağmen devam edeceklerdir. Çünkü başarılı olacaklarına inanırlar (Carver ve Scheier, 2002).

Horton ve Wallander (2001), engelli çocuğa sahip 111 anneyle yaptıkları çalışmada, umudun hem anne üzerinde doğrudan bir etkisi olduğunu, hem de refahı arttırdığını ve aynı zamanda umudun bir tampon görevi gördüğünde ılımlı bir etkiye sahip olduğunu bulmuşlardır. Umut aynı zamanda psikolojik sorunlarla negatif, iyi oluşla (Cheavens vd., 2006), sağlıkla ilgili olumlu başa çıkmayla (Irving, Snyder ve Crowson, 1998) ve sağlığa uyumla olumlu bir ilişki içindedir.

Sosyal desteğin zihinsel yetersizliği olan çocukların ebeveynleri için de önemli olduğu gösterilmiştir. İyimserliği yüksek olanların çevrelerinden sosyal destek almayı daha kolay bulması olasıdır çünkü insanlar iyimserliği yüksek olanlara kötümser olanlara göre daha olumlu 
yanıt verme eğilimindedir. İyimserler için kendilerini destekleyecek başkalarını çekmek daha kolay olabilir. İyimserliği yüksek olanların daha yüksek sosyal desteğe sahip oldukları görülmüş ve stres yaşadıklarında sosyal destekte artış eğilimi göstermişlerdir (Pratt vd., 2001). Snyder (2000), zorluklarla yüzleşebilmek için umudun hayati olduğunu öne sürmüştür.

İyimserliği ve umudu yüksek olanlar daha olumlu başa çıkma stratejileri kullanırlar ve bu ebeveynler için de önemlidir. İyimser ebeveynler daha sağlıklıdır ve iyimserliklerini olumlu başa çıkma ve problem çözmeyi kolaylaştırmak için kullanırlar (Pratt vd., 2001). Umut, stres karşısında etkili başa çıkma ile ilişkilendirilmiştir ve ayrıca bir kontrol duygusu ile ilişkilendirilmiştir. Umutları yüksek olanlar, hedef arayışları boyunca başarısızlıklardan ziyade başarılara odaklanma eğilimindedir (Snyder, 2000).

Parks ve Layous'a (2016) göre, pozitif psikoloji yaklaşımına yönelik müdahale yöntemlerinin ana amacı; bireylerin tüm potansiyelini işlevsel olarak kullanabilmesi olarak da tanımlanan psikolojik iyi oluşunu artırmaktır. Carr vd. (2020), 41 ülkede 347 çalışmayı inceledikleri bir metaanaliz çalışmasında görüldüğü üzere pozitif psikoloji müdahalelerinin birlikte ele alındığı oturum yapılanmalarının daha etkili sonuçlar ortaya çıkardığı yönündedir. $\mathrm{Bu}$ anlamda çalışmanın geri kalan bölümünde pozitif psikoloji alanında psikolojik iyi oluşun artırılmasını hedef alan müdahale yöntemlerine yer verilecektir.

\section{Pozitif Psikolojide Terapötik Müdahale Yöntemleri}

Pozitif psikoloji, psikoloji alanında nispeten yeni bir yaklaşımdır. Temelde şimdiye kadar ortaya çıkan özel bakış açıları ve terapötik yaklaşımları nedeniyle psikolojide dikkate değer bir konum kazanmıştır. Özellikle yaşam kalitesini, mutluluğu ve iyi oluşu artırmaya yönelik ampirik, kanıta dayalı pragmatik yaklaşımlar geliştirmesi sebebiyle ilgi duyulmaya başlanmıştır (Joseph ve Linley, 2006). Ayrıca hem önlemede hem de tedavide geliştirilen programlar aracılığıyla, günümüz bilimsel araştırmalarına yeni alanlar kazandırmıştır.

Pozitif psikoloji müdahaleleri, psikolojik iyi oluşu artırmayı, olumlu duygular, davranışlar ve bilişler oluşturmayı amaçlar (Sin ve Lyubomirsky, 2009). Ruh sağlığı semptomlarının tedavisine yönelik bu geleneksel olmayan yaklaşım, olumlu duyguların inşasının semptomlarda azalma ile ilişkili olacağını düşündürmektedir. Bu müdahaleler, zayıf yönleri açılarken aynı zamanda güçlü yönleri geliştirmeye odaklanır. Katılımcılara, dikkatlerini ve hafızalarını yaşamın olumlu yönlerine ve özelliklerine yeniden odaklayacak stratejiler öğretilir (Rashid, 2009). Pozitif psikoloji müdahalelerinin bir meta-analizinde araştırmacılar, şükran mektupları yazmanın, iyimser düşünceyi ele almanın, olumlu deneyimleri tekrarlamanın ve sosyalleşmenin psikolojik iyi oluşu artırdığını ve depresyon semptomlarını etkili bir şekilde tedavi edebildiğini bulmuşlardır (Lyubomirsky vd., 2011; Sin ve Lyubomirsky, 2009). 
Pozitif psikoloji müdahalelerine yönelik eğitim ve psikoterapi alanında yapılan deneysel çalışmalarda hastalık semptomlarının azaltılması ve önlenmesinde, olumlu duyguların ve deneyimlerin, mutluluğun, iyimserliğin, yaşam doyumunun ve yaşam kalitesinin artmasında etkili olduğu ortaya konulmuştur (Rashid ve Seligman, 2013; Seligman vd., 2005; Seligman, Rashid ve Parks, 2006; Sin ve Lyubomirsky, 2009). Rashid ve Seligman'ın (2013), "Pozitif Psikoterapi"si, pozitif psikoloji alanındaki en etkili müdahalelerden biridir.

Rashid ve Seligman'ın pozitif psikoterapisi, pozitif psikolojinin kurucusu Martin Seligman'ın yazarlardan biri olması nedeniyle, çağdaş pozitif psikolojiden psikoterapi pratiğine kadar tüm bulguların önemli bir uygulamasıdır (Rashid, 2013). Martin Seligman, mutluluk konusunda ortaya koyduğu PERMA adını verdiği model ile iyi oluşa ve işlevsel yaşama ulaşma yollarını tanımlamıștır. Seligman (2012), pozitif psikoloji kavramının sadece odaklandığı şeyin mutluluk olmadığına; asıl hedefin tam potansiyele uygun bir yaşam olduğunu söylemiştir. Bu teoride pozitif psikolojinin konusu iyilik halidir. Gerçekleşmesi için gerekli altyapı ve bağlamların sağlandığı beş ölçülebilir bileșenden oluşur. Bunlar: olumlu duygular (iki yönü mutluluk ve yaşam doyumudur), bağlılık, anlam, olumlu ilişki ve başarıdır.

Rashid ve Seligman'ın (2013), 14 oturumluk "Pozitif Psikoterapi"si, yapılandırılmış müdahaleler ve ilgili ev ödevleri yoluyla Seligman'ın keyifli yaşam, meşgul yaşam ve anlamlı yaşam olarak adlandırdığı iyi oluşun üç temel yolunu ele alır. Program, hazzı artıran ve keyifli yaşamı teşvik eden yaşamda zevk alma gibi müdahaleleri içerir. Pozitif psikoterapi sürecinin ilk oturumlarında pozitif kaynakların belirlenmesi, güçlü yanların ortaya çıkarılması ve kişiye özgü pozitif duyguların ele alınmasına yönelik çalışmalar yapılır. Terapinin orta aşamasında geçmişte yaşanmış olumsuz etki uyandıran anılara karşı iyi anıların çalışması yapılır. İlerleyen aşamada affetme ve şükran uygulamalarına yer verilir. Son aşamada ise umut ve iyimserlik konuları ele alınır ve kişinin yapmaktan zevk aldığı etkinlikler konusunda farkındalık elde etmesi amaçlanır. Daha sonra kişinin güçlü yanlarını diğer insanlar üzerinde kullanması ve onlara destek olması yönünde çalışmalar yapılarak terapötik süreç sonlandırılır (Rashid, 2015).

İyi oluş terapisi, bilişsel davranış̧̧ı terapiye ve Ryff'ın psikolojik iyi oluş modeline dayanan bir pozitif psikoloji müdahalesidir (Ryff, 1989). Tedavi, refahı artırmak için bilişsel yeniden yapılandırma tekniklerini öğretmeye ve ardından bu becerileri, psikolojik iyi oluşun altı boyutunu katılımcıların yaşamlarına entegre etmek için kullanırken, düşünmedeki hatalara dayalı müdahaleyi azaltmak için stratejiler kullanmaya odaklanır (Fava ve Ruini, 2003). İyi oluş terapisinin majör depresif bozukluk, yaygın anksiyete bozukluğu, obsesif kompulsif bozukluk ve travma sonrası stres bozukluğu olan kişiler de dahil olmak üzere farklı popülasyonlarda ruh hali ve işlevsellik üzerinde önemli bir etkisi olduğu bulunmuştur (Fava ve Tomba, 2009). 
Pozitif psikoterapi modellerinden biri de 1960'lı yllarda Peseschkian tarafından geliştirilen sosyo-kültürel faktörleri de dikkate alan terapi modelidir. Bu yaklaşıma göre bireyler bütüncül yaşantıları ile ele alınır ve insan doğasına bakış açısı bireyin geçmişten bu zamana geliştirdiği gerçek kapasiteleri üzerinedir. Bu anlamda psikodinamik bir özellik de taşımaktadır. Peseschkian'ın pozitif psikoterapisi üç temel ilke üzerine yapılandırılmıştır. Bunlar umut, konsültasyon ve dengedir. Bu modele göre insan sevme ve bilme olarak adlandırılan iki temel yetenek üzerinden değerlendirilir. Sevme yeteneği birincil yetenekler olarak değerlendirilir ve bunlar: sabır, güven, cinsellik, umut, zaman, inanç ve temastır. Bilme yeteneği ise insanların öğrenme yetenekleri olarak ilişkilendirilir ve ikincil yetenekler olarak isimlendirilir. Bunlar ise; dürüstlük, nezaket, kibarlık, dakik olma, güvenirlik, temizlik, sadakat, tutumluluktur (Peseschkian, 2015).

Peseschkian'ın pozitif psikoterapisinde süreç beş basamaktan oluşmaktadır (Eryılmaz, 2017). Birinci basamak gözlem evresidir. Bu aşamada danışmaya gelen bireyin problemi denge modeli çerçevesinde(başarı, maneviyat, bireysel gelişim, beden) ele alınır. İkinci aşamada envanter aşamasıdır. Burada danışanların yetenekleri karakter ölçeği vasıtası belirlenir. Üçüncü aşamada danışanların güçlü özellikleri üzerinde durulur ve yaşadıkları psikolojik duruma ilişkin pozitif çıkarımlar yapılır. Dördüncü aşamada ise süreç boyunca hazırlanan plan uygulanır ve iletişim becerileri üzerinde durulur. Son aşamada ise danışanların denge modeli çerçevesinde geleceğe ilişkin hedefler belirlemeleri ve hedeflere ilişkin plan hazırlamaları üzerine çalışılır (Peseschkian, 2015).

Yukarıda görüldüğü üzere literatürde başlıca ele alınan pozitif psikoloji akımını temsil eden yaklaşımlar incelenmiştir. Yaklaşımların temel özelliği bireyleri sadece olumsuz ruh halleri veya yaşadıkları problem üzerinden değil; bireylerin güçlü yanlarını ele alarak bütüncül bir bakıș açısıyla değerlendirmektir. Bu anlamda bireylerin sahip olduğu olumlu özellikler geliştirilerek yaşamın geri kalan bölümü için daha güçlü bir benlik inşa etme üzerine çalışmalar yapılmaktadır.

\section{YÖNTEM}

\section{Araştırmanın Modeli}

$\mathrm{Bu}$ çalışma zihinsel yetersizliği olan çocuğa sahip annelerin yaşadığı psikolojik ve duygusal süreci pozitif psikoloji akımı ile ortaya koyan bir derleme çalışmasıdır. Derleme; belirli bir konu alanında yapılan araştırmaların özet ve sentezinden oluşan güncel alanyazına katkı sunan çalışmalardır (Herdman, 2006).

\section{Alanyazın Taraması}


Çalışma kapsamında zihinsel yetersizliği olan bireylerin annelerine yönelik pozitif psikoloji kavramlarını ele alan ulusal ve uluslararası araştırmalar incelenmiştir. Alanyazın inceleme aşamasında Türkçe ve İngilizce olarak "zihinsel yetersizlik", "pozitif psikoloji", "iyi oluş", "umut", "iyimserlik" ve "öz anlayış" kavramları anahtar sözcük olarak kullanılmıştır. İlgili alanyazın taranırken YÖK tez veri tabanı, ULAKBİLIM veri tabanı ve Google Scholar sayfalarından yararlanılmıştır. Araştırma kapsamında incelenen çalışmalar Tablo 1'de şu şekilde özetlenmiştir:

\section{Tablo 1}

İncelenen çalışmaların temel özellikleri

\begin{tabular}{|c|c|c|}
\hline Yazar & Tarih & Araştırma Konusu \\
\hline Atagün, M.İ. vd. & 2011 & Kronik hastalıklarda bakım veren yükü. \\
\hline Bekhet, A. K. vd.. & 2012 & $\begin{array}{l}\text { Otizm spektrum bozukluğu olan kişilere bakıcıların dayanıklılıklarına etkisi: } \\
\text { olumlu bilişlerin rolü }\end{array}$ \\
\hline Cappe, E., vd. & 2011 & $\begin{array}{l}\text { Yaşam kalitesi: Otizm spektrum bozukluğu olan çocukların ebeveynlerinde } \\
\text { uyumun değerlendirilmesinde ve ilgili destek ve yardım programlarının } \\
\text { geliştirilmesinde dikkate alınması gereken kilit bir değişken. }\end{array}$ \\
\hline Carr, A. vd. & 2020 & $\begin{array}{l}\text { Pozitif psikoloji müdahalelerinin etkinliği: sistematik bir inceleme ve meta- } \\
\text { analiz. }\end{array}$ \\
\hline Crabtree, S.A. & 2007 & Arap Emirlikleri'nde gelişimsel engelli çocukların sosyalliği ve aile tepkileri. \\
\hline Conner, C.M. vd. & 2014 & Otizmli çocukların annelerinde stres: koruyucu bir faktör olarak farkındalık. \\
\hline Cooke, J. E. & 2010 & $\begin{array}{l}\text { Zihinsel yetersizliği olan çocuğa sahip ailelerde umut, iyimserlik ve sosyal } \\
\text { destek. }\end{array}$ \\
\hline Cox, C. R. vd. & 2015 & $\begin{array}{l}\text { Otizm spektrum bozukluğu olan çocukların annelerinde ölüm kaygları ve } \\
\text { psikolojik iyi olma hali. }\end{array}$ \\
\hline Desiningrum, D. & 2018 & Yaşlılarda psikolojik iyi olma hali: otistik çocuğu olan ailelerde bir çalışma. \\
\hline Ellis, J.B. vd. & 2000 & Gelişimsel olarak gecikmiş çocukların ebeveynlerinde yaşama nedenleri. \\
\hline $\begin{array}{l}\text { Fernandez, M. C., } \\
\text { \& Arcia, E. }\end{array}$ & 2004 & $\begin{array}{l}\text { Yıkıcı davranışlar ve anne sorumluluğu: damgalama, kendini suçlama ve } \\
\text { diğer tepkilerin karmaşık bir portresi. }\end{array}$ \\
\hline Gatford, A. & 2007 & Down sendromu: farklı kültürlerden annelerin deneyimleri \\
\hline $\begin{array}{l}\text { Hayat, I. ve Zafar, } \\
\text { M. }\end{array}$ & 2015 & $\begin{array}{l}\text { Down sendromlu çocukları olan ebeveynlerde psikolojik iyi oluş ve başa } \\
\text { çıma stratejileri arasındaki ilişki. }\end{array}$ \\
\hline $\begin{array}{l}\text { Horton, T. V., \& } \\
\text { Wallander, J. L. }\end{array}$ & 2001 & $\begin{array}{l}\text { Kronik fiziksel rahatsızlığı olan çocuğa bakım veren annelerin psikolojik } \\
\text { sıkıntılarına karşı dayanıklılık faktörleri olarak umut ve sosyal destek. }\end{array}$ \\
\hline Hsiao, Y.-J. & 2016 & $\begin{array}{l}\text { Otizm spektrum bozukluğu olan çocukların ebeveynlerinde yaşam kalitesi } \\
\text { ebeveyn stresinin rolleri, çocukların performansı, tıbbi destek ve sosyal } \\
\text { destek. }\end{array}$ \\
\hline Johnson, N. vd. & 2011 & $\begin{array}{l}\text { Otizm spektrum bozukluğu: Ebeveynlik stresi ve sağlıkla ilgili yaşam } \\
\text { kalitesi. }\end{array}$ \\
\hline Kashdan, T. B. vd. & 2002 & $\begin{array}{l}\text { Dişsallaştırma bozukluğu olan çocukların ebeveynlerinde insan gücü olarak } \\
\text { umut ve iyimserlik. }\end{array}$ \\
\hline $\begin{array}{l}\text { Mak, W., \& Kwok, } \\
\text { Y. }\end{array}$ & 2010 & $\begin{array}{l}\text { Hong Kong'da otizm spektrum bozukluğu olan çocukların ebeveynleri için } \\
\text { damgalanmanın içselleștirilmesi }\end{array}$ \\
\hline
\end{tabular}




\begin{tabular}{|c|c|c|}
\hline Miller, V. A. vd. & 2012 & Otistik çocukların ebeveynlerinde tedavi seçimleriyle ilgili faktörler. \\
\hline Mitchell, A. E. vd. & 2018 & $\begin{array}{l}\text { Bebeklerin anneleri için kısa bir çevrimiçi öz-şefkat müdahalesinin } \\
\text { uygulanabilirliği ve kabul edilebilirliği. }\end{array}$ \\
\hline Myers, R. E. vd. & 2014 & Gelişimsel yetersizliklerde farkındalık meditasyonu. \\
\hline $\begin{array}{l}\text { Neff, K. D., \& Faso, } \\
\text { D. J. }\end{array}$ & 2015 & Otizmli çocukların ebeveynlerinde öz-şefkat ve iyilik hali. \\
\hline Sari, H.Y. vd. & 2006 & Down sendromlu çocuğa sahip annelerin deneyimleri. \\
\hline $\begin{array}{l}\text { Sin, N., \& } \\
\text { Lyubomirsky, S. }\end{array}$ & 2009 & $\begin{array}{l}\text { Pozitif psikoloji müdahaleleri ile iyi oluşu artırmak ve depresif semptomları } \\
\text { hafifletmek: bir meta-analiz çalışması. }\end{array}$ \\
\hline Vural-Yüzbaşı, D. & 2018 & $\begin{array}{l}\text { Zihinsel engelli çocuğa sahip annelerin iyi oluşlarının başa çlkma tarzları, } \\
\text { aile gereksinimleri ve sosyal destek değişkenleriyle modellenmesi. }\end{array}$ \\
\hline $\mathrm{Xu}, \mathrm{Y}$. & 2007 & $\begin{array}{l}\text { Engelli küçük çocukların kültürel açıdan farklı ailelerini güçlendirmek: Çift } \\
\text { ABCX Modeli. }\end{array}$ \\
\hline
\end{tabular}

\section{Etik Onay}

Araştırmanın etik onayı Eskişehir Osmangazi Üniversitesi Sosyal ve Beşeri Bilimler Bilimsel Araştırma ve Yayın Etiği Kurulundan 28.10.2020 tarihli 2020-20 sayılı karar ile alınmıştır.

\section{TARTIŞMA, SONUÇ VE ÖNERÍLER}

Sonuç olarak zihinsel yetersizliği tanısı alan bir çocuğa sahip olan ebeveynler birçok zorluğa maruz kalmakta psikolojik olarak da çeşitli evreler atlatmaktadır. Ailelerin ve özellikle annelerin yaşadıkları duygusal süreçten bir an önce çıkıp duruma uyum sağlamaları hem kendileri hem de aileleri için büyük önem arz eder. Nitekim zihinsel yetersizliği olan bir birey için amaç potansiyelinin en üst seviyesine çıkıp bağımsız bir birey olarak yaşamasını sağlamaktır. Buradaki temel görev de ebeveynlere düşmektedir. Bu anlamda çocuğun bağımsızlığında umut geliştirmek, ebeveynlerin olumlu duygularını ve iyi oluşunu artırmak açısından çok önemlidir (Cooke, 2010; Seligman, 2012). Ayrıca bu ailelerde dayanıklılığa katkıda bulunan güçlü yönleri belirleyerek, bu kaynakları güçlendirmek ve böylece uyum sağlamakta zorlanan ailelerde başa çıkmayı kolaylaştırmak için müdahaleler ve destek programları uygulanabilir (Ellis ve Hirsch, 2000). Aile biriminin bu şekilde güçlendirilmesi önemlidir, çünkü ailenin esenliği, gelişimsel engelli çocuk da dahil olmak üzere bireysel üyelerinin esenliğini ve uyumunu etkiler (Walsh, 2003).

Pozitif psikolojinin diğer alt çalışma alanlarından farkı insan hayatının pozitif noktalarına odaklanmaktır. Psikolojinin patolojik kavramları yerine olumlu kavramlarla yapılan çalışmalar artış göstermektedir. Bireylerin kıskançlık ve çekememezlik duygularına yerine şükran-minnettarlık kavramı, cinsellik ve saldırganlık yerine öz denetim, dürüstlük, affetme, yaratıcılık kavramlarına, depresyon ve anksiyete yerine mutluluk, umut, iyimserlik gibi 
kavramlar çalışılmaktadır (Sheldon, Kashdan ve Steger, 2011). Uluslarası literatürde çalışmaların yayımlandığı Pozitif Psikoloji Dergisi'ne (Journal of Positive Psychology) bakıldığında karakter güçleri, erdemler, akış, affetme, şükran, empati, iyi oluş, zevk, iyimserlik ve umut konularında yapılan çalışmalar göze çarpar. Bu anlamda pozitif psikoloji insanın yaşam tatminini artıracak, fonksiyonlarını geliştirecek pozitif doğasına odaklanan bir çalışma alanı olarak açılklanabilir (Lyubomirsky vd., 2011).

Khanjani (2017), araştırmasında, Seligman'ın PERMA modeline dayalı programın Pennsylvania Dayanıklılık Programına kıyasla depresyon, kaygı ve stres belirtilerini azaltmada ve ayrıca yaşam doyumunu, iyimserliği ve psikolojik sağlığı artırmada daha etkili olduğunu ortaya koymuştur. Genel olarak, pozitif psikoterapinin etkinliği üzerine yürütülen ampirik çalışmaların sonuçları, mevcut yaklaşımın bir yandan stres, kaygı, depresyon ve diğer duygusal sıkıntı semptomlarını azalttığını ve mutluluğu, yaşam doyumunu ve iyimserliği ve insanların psikolojik iyi oluşunu artırdığını belirtmektedir. Smeets vd. (2014), 3 haftalık öz anlayışa dayalı bir grup müdahalesinin kadınların psikolojik sağlamlık, iyi oluş, öz anlayış, iyimserlik ve öz yeterlilik üzerinde önemli etkiler oluşturduğunu göstermektedir.

Pozitif psikoloji müdahalelerinin etkilerine yönelik yapılan metaanaliz çalıșmalarında da araştırma bulgularını destekleyecek çalışmalara rastlanmıştır. Weiss, Westerhof ve Bohlmeijer (2016), ise 3579 kişinin psikolojik iyi oluş düzeyleri üzerinde pozitif psikoloji müdahalelerinin etkisini inceledikleri 27 araştırmada küçük düzeyde olumlu etkilerin bulunduğunu keşfetmişlerdir. Drozd vd. (2014), şükran, hoş aktiviteler, güçlü yönler, ustalık, iyimserlik, akış ve farkındalığı ele aldıkları müdahalelerin iyi oluş üzerinde araştırma bulguları ile uyumlu olarak olumlu ve umut verici etkilerini tespit etmişlerdir.

Araștırma sonuçlarında da görüldüğü üzere pozitif psikoloji akımına yönelik müdahalelerin yetişkinlerde psikolojik iyi oluşu, umudu, öz anlayıșı, yaşam doyumu ve kalitesini, iyimserliği arttırdığı gözlemlenmiştir. Bunun yanında pozitif psikoloji literatürü incelendiğinde zihinsel yetersizliği olan bireylerin ebeveynlerine yönelik çalışmaların sınırlı sayıda olduğu görülmüştür. Bu çalışmanın da amacı zihinsel yetersizliği olan çocukların annelerinin psikolojik durumlarını pozitif psikoloji akımı çerçevesinde değerlendirmektir. Bundan sonraki çalışmalarda ise bu ailelerin annelerine yönelik yapılacak pozitif psikoloji temelli deneysel ve ampirik araştırmaların literatüre zenginlik katacağı düşünülmektedir. 


\section{KAYNAKÇA}

Altiere, M. J., \& Von Kluge, S. (2009). Family functioning and coping behaviors in parents of children with autism. Journal of Child and Family Studies, 18(1), 83-92. https://doi.org/10.1007/s10826-008-9209-y

Atagün, M.İ., Balaban, Ö.D., Atagün, Z., Elagöz, M. ve Özpolat, A.Y. (2011). Kronik hastalıklarda bakım veren yükü. Psikiyatride Güncel Yaklaşımlar, 3(3), 513-552. https://doi.org/10.5455/cap.20110323

Bekhet, A. K., Johnson, N. L., \& Zauszniewski, J. A. (2012). Effects on resilience of caregivers of persons with autism spectrum disorder: The role of positive cognitions. Journal of the American Psychiatric Nurses Association, 18(6), 337-344. https://doi.org/10.1177\%2F1078390312467056

Bishop, S. R., Lau, M., Shapiro, S., Carlson, L., Anderson, N. D., Carmody, J., \& ... Devins, G. (2004). Mindfulness: a proposed operational definition. Clinical Psychology: Science and Practice, 11(3), 230-241. https://doi.org/10.1093/clipsy.bph077

Bögels, S. M., Lehtonen, A., \& Restifo, K. (2010). Mindful parenting in mental health care. Mindfulness, 1(2), 107-120. https://dx.doi.org/10.1007\%2Fs12671-010-0014-5

Cappe, E., Wolff, M., Bobet, R., \& Adrien, J.-L. (2011). Quality of life: A key variable to consider in the evaluation of adjustment in parents of children with autism spectrum disorders and in the development of relevant support and assistance programmes. Quality of Life Research, 20(8), 1279-1294. https://doi.org/10.1007/s11136-011-9861-3

Carr, A., Cullen, K., Keeney, C., Canning, C., Mooney, O., Chinseallaigh, E., \& O’Dowd, A. (2020). Effectiveness of positive psychology interventions: a systematic review and metaanalysis. The Journal of Positive Psychology, 15(5), 1-21. https://doi.org/10.1080/17439760.2020.1818807

Carver, C. S., \& Scheier, M. F. (2002). The hopeful optimist. Psychological Inquiry 13(4), 288-290.

Cheavens, J. S., Feldman, D. B., Gum, A., Michael, S. T., \& Snyder, C. R. (2006). Hope therapy in a community sample: A pilot investigation. Social Indicators Research, 77(1), 61-78. http://dx.doi.org/10.1007/s11205-005-5553-0

Crabtree, S.A. (2007). Family responses to the social inclusion of children with developmental disabilities in the United Arab Emirates. Disability \& Society, 22(1), 49-62. http://dx.doi.org/10.1080/09687590601056618

Coatsworth, J. D., Duncan, L. G., Greenberg, M. T., \& Nix, R. L. (2010). Changing parent's mindfulness, child management skills and relationship quality with their youth: results from a randomized pilot intervention trial. Journal of Child and Family Studies, 19(2), 203-217. https://dx.doi.org/10.1007\%2Fs10826-009-9304-8

Conner, C.M., \& White, S.W. (2014). Stress in mothers of children with autism: trait mindfulness as a protective factor. Research in Autism Spectrum Disorders, 8(6), 617-624. http://dx.doi.org/10.1016/j.rasd.2014.02.001

Cooke, J. E. (2010). Hope, optimism, stress, and social support in parents of children with intellectual disabilities [Unpublished Master's Thesis]. The University of Southern Mississippi.

Cox, C. R., Eaton, S., Ekas, N. V., \& Van Enkevort, E. A. (2015). Death concerns and psychological well-being in mothers of children with autism spectrum disorder. Research in Developmental Disabilities, 45(46), 229-238. https://doi.org/10.1016/j.ridd.2015.07.029 
Deniz, M. E. Sahin, K., \& Sümer, S. A. (2008). The validity and reliability of the turkish version of the self-compassion scale. Social Behavior and Personality, 36(9), 1151-1160. http://dx.doi.org/10.2224/sbp.2008.36.9.1151

Desiningrum, D. R. (2018). Grandparents' roles and psychological well-being in the elderly: a correlational study in families with an autistic child. Enfermeria Clinica, 28(1), 304-309. https://doi.org/10.1016/S1130-8621(18)30175-X

Drozd, F., Mork, L., Nielsen, B., Raeder, S., \& Bjørkli, C. A. (2014). Better days A randomized controlled trial of an internet-based positive psychology intervention. The Journal of Positive Psychology, 9(5), 377-388. https://doi.org/10.1080/17439760.2014.910822

Ellis, J.B., \& Hirsch, J.K. (2000). Reasons for living in parents of developmentally delayed children. Research in Developmental Disabilities, 21(4), 323-327. https://doi.org/10.1016/S0891-4222(00)00045-7

Eryılmaz, A. (2017). Pozitif psikoterapiler. Psikiyatride Güncel Yaklaşımlar, 9(3), 346-362. https://doi.org/10.18863/pgy.288667

Fava, G. A., \& Ruini, C. (2003). Development and characteristics of a well-being enhancing psychotherapeutic strategy: Well-being therapy. J Behav Ther Exp Psychiatry, 34(1), 4563. https://doi.org/10.1016/S0005-7916(03)00019-3

Fava, G. A., \& Tomba, E. (2009). Increasing Psychological Well-Being and Resilience by Psychotherapeutic Methods. Journal of Personality, 77(6), 1903-1934. https://doi.org/10.1111/j.1467-6494.2009.00604.x

Fernandez, M. C., \& Arcia, E. (2004). Disruptive behaviors and maternal responsibility: a complex portrait of stigma, self-blame, and other reactions. Hispanic Journal of Behavioral Sciences, 26(3), 356-372. http://dx.doi.org/10.1177/0739986304267208

Gatford, A. (2007). Down's syndrome: experiences of mothers from different cultures. British Journal of Nursing, 10(18), 1193-1199. http://dx.doi.org/10.12968/bjon.2001.10.18.9940 Gray, D. (1993). Perceptions of stigma: the parents of autistic children. Sociology of Health \& Illness, 15(1), 102-120. https://doi.org/10.1111/1467-9566.ep11343802

Hayat, I., \& Zafar, M. (2015). Relationship between Psychological Well-Being and Coping Strategies among Parents with Down syndrome children. International Journal of Humanities and Social Science, 5(7), 109-117.

Hefferon, K., \& Boniwell, I. (2014). Pozitif psikoloji: Kuram, araștırma ve uygulamalar. (T. Doğan, Çev. Ed.). Nobel Akademik Yayıncılık.

Herdman, EA. (2006). Derleme makale yazımında, konferans ve bildiri sunumu hazırlamada pratik bilgiler. Hemşirelikte Eğitim ve Araștırma Dergisi, 3(1), 2-4. https://jag.journalagent.com/kuhead/pdfs/KUHEAD_3_1_2_4.pdf

Hollis-Walker, L., \& Colosimo,K. (2011). Mindfulness, self-compassion, and happiness in nonmeditators: a theoretical and empirical examination. Personality and Individual Differences, 50(2), 222-227. https://doi.org/10.1016/j.paid.2010.09.033

Horton, T. V., \& Wallander, J. L. (2001). Hope and social support as resilience factors against psychological distress of mothers who care for children with chronic physical conditions. Rehabilitation Psychology, 46(4), 382-399. https://doi.org/10.1037/0090-5550.46.4.382

Hsiao, Y.-J. (2016). Pathways to mental health-related quality of life for parents of children with autism spectrum disorder: roles of parental stress, children's performance, medical support, and neighbor support. Research in Autism Spectrum Disorders, 23(8), 122-130. https://doi.org/10.1016/j.rasd.2015.10.008 
Irving, L. M., Snyder, C. R., \& Crowson, J. J. (1998). Hope and coping with cancer by college women. Journal of Personality, 66(2), 195-214. https://doi.org/10.1111/14676494.00009

Johnson, N., Frenn, M., Feetham, S., \& Simpson, P. (2011). Autism spectrum disorder: Parenting stress, family functioning and health-related quality of life. Families, Systems, \& Health, 29(3), 232-252. https://doi.org/10.1037/a0025341

Jose, A., Gupta, S., Gulati, S., \& Sapra, S. (2017). Prevalence of depression in mothers of children having ASD. Current Medicine Research and Practice, 7(1), 11-15. https://doi.org/10.1016/j.cmrp.2016.12.003

Kashdan, T. B., Pelham, W. E., Lang, A. R., Hoza, B., Jacob, R. G., Jennings, J. R., Blumenthal, J. D., \& Gnagy, E. M. (2002). Hope and optimism as human strengths in parents of children with externalizing disorders: stress is in the eye of the beholder. Journal of Social and Clinical Psychology, 21(4), 441-468. http://dx.doi.org/10.1521/jscp.21.4.441.22597

Keyes, C. L., Shmotkin, D., \& Ryff, C. D. (2002). Optimizing well-being: the empirical encounter of two traditions. Journal of personality and social psychology,82(6), 1007-1022. https://doi.org/10.1037/0022-3514.82.6.1007

Khanjani, M. (2017). The impact of positive psychotherapy on decreasing the college students' stress, anxiety, depression and increasing their well-being. Quarterly of Clinical Psychology Studies Allameh Tabataba'i University, 7(28), 107-119. https://doi.org/10.22054/JCPS.2017.8158

Koydemir, S., \& Tosun, Ü. (2009). Impact of autistic children on the lives of mothers. Procedia Social and Behavioral Sciences, 1(1), 2534-2540. https://doi.org/10.1016/j.sbspro.2009.01.447

Linley, A. (2009). Positive psychology. In S. Lopez (Ed.). The encyclopedia of positive psychology (pp.670-816). Blackwell Publishing Ltd. https://doi.org/10.1002/9781444306002.ch16

Luthans, F. (2002). Positive organizational behavior: developing and managing psychological strengths. Academy of Management Executive, 16(1), 57-72. http://dx.doi.org/10.5465/AME.2002.6640181

Lyubomirsky, S., Dickerhoof, R., Boehm, J.K., \& Sheldon, K.M. (2011). Becoming happier takes both a will and a properway: an experimental longitudinal intervention to boost wellbeing. Emotion, 11(2), 391-402. https://doi.org/10.1037/a0022575

Mak, W., \& Kwok, Y. (2010). Internalization of stigma for parents of children with autism spectrum disorder in Hong Kong. Social Science \& Medicine, 70(12), 2045-2051. https://doi.org/10.1016/j.socscimed.2010.02.023

Miller, V. A., Schreck, K. A., Mulick, J. A., \& Butter, E. (2012). Factors related to parents' choices of treatments for their children with autism spectrum disorders. Research in Autism Spectrum Disorders, 6(1), 87-95. http://dx.doi.org/10.1016/j.rasd.2011.03.008

Mitchell, A. E., Whittingham, K., Steindl, S., \& Kirby, J. (2018). Feasibility and acceptability of a brief online self-compassion intervention for mothers of infants. Archives of Women's Mental Health, 21(5), 553-561. https://doi.org/10.1007/s00737-018-0829-y

Myers, R. E., Winton, A. S. W., Lancioni, G. E., \& Singh, N. N. (2014). Mindfulness meditation in developmental disabilities. In N. N. Singh (Ed.), Psychology of meditation (pp. 209-240). Nova.

Neff, K. D. (2003). Self-compassion: an alternative conceptualization of a healthy attitude toward oneself. Self and İdentity, 2(2), 85-101. https://doi.org/10.1080/15298860309032 
Neff, K. D., Pisitsungkagarn, K., \& Hseih, Y. (2008). Self-compassion and self-construal in the United States, Thailand, and Taiwan. Journal of Cross-Cultural Psychology, 39(3), 267285. https://doi.org/10.1177\%2F0022022108314544

Neff, K. D. (2011). Self-compassion, self esteem, and well being. Social and Personality Psychology Compass, 5(1), 1-12. http://dx.doi.org/10.1111/j.1751-9004.2010.00330.x

Neff, K. D., \& Beretvas, S. (2013). The role of self-compassion in romantic relationships. Self and Identity, 12(1), 78-98. https://doi.org/10.1080/15298868.2011.639548

Neff, K. D., \& Faso, D. J. (2015). Self-compassion and well-being in parents of children with autism. Mindfulness, 6(4), 938-947. https://doi.org/10.1007/s12671-014-0359-2

Parks, A. C., \& Layous, K. (2016). Positive psychological interventions. In J. C. Norcross, G. R. VandenBos, D. K. Freedheim, \& R. Krishnamurthy (Eds.). APA handbook of clinical psychology: Applications and methods, 3, 439-449. https://doi.org/10.1037/14861-023

Peseschkian, N. (2015). Positive psychotherapy: Theory and practice of a new method. Springer Science \& Business Media.

Pratt, M. W., Norris, J. E., van de Hoef, S., \& Arnold, M. L. (2001). Stories of hope: Parental optimism in narratives about adolescent children. Journal of Social and Personal Relationships, 18(5), 603-623. https://doi.org/10.1177/0265407501185003

Rand-Kevin, L., \& Chavens-Jennifer S. (2009). Hope Theory. Shane J. Lopez \& C.R. Snyder (Eds.), Oxford handbook of positive psychology (pp. 257-276). Oxford University.

Rashid, T. (2009). Positive psychotherapy. Praeger Publishers.

Rashid, T., \& Seligman, M. E. P. (2013). Positive psychotherapy: A treatment manual. Oxford University Press.

Rashid, T. (2015). Positive psychotherapy: A strength-based approach. The Journal of Positive Psychology, 10(1), 25-40. http://dx.doi.org/10.1080/17439760.2014.920411

Ryff, C. D. (1989). Happiness is everything, or is it? Explorations on the meaning of psychological well-being. Journal of Personality and Social Psychology, 57(6), 1069- 1081. https://doi.org/10.1037/0022-3514.57.6.1069

Ryff, C.D., \& Keyes, C.L.M. (1995). The structure of psychological well-being revisited. Journal of Personality and Social Pscychology, 69(4), 720-728. https://doi.org/10.1037//00223514.69.4.719

Sari, H.Y., Baser, G., \& Turan, J. M. (2006). Experiences of mothers of children with Down $\begin{array}{llll}\text { syndrome. } & \text { Paediatric } & \text { 29-32. }\end{array}$ https://doi.org/10.7748/paed2006.05.18.4.29.c1024

Scheier, M. F., \& Carver, C. S. (1985). Optimism, coping, and health: Assessment and implications of generalized outcome expectancies. Health Psychology, 4(3), 219-247. https://doi.org/10.1037/0278-6133.4.3.219

Seligman, M. E. P., \& Csikszenmihalyi, M. (2000). Positive psychology. American Psychologist, 55(1), 5-14. http://dx.doi.org/10.1037/0003-066X.55.1.5

Seligman, M.E.P. (2002). Positive psychology, positive prevention and positive therapy. In C.R. Snyder \& S.J. Lopez (Eds.). Handbook of positive psychology (pp. 3-9). Oxford University Press.

Seligman, M.E.P., Steen, T., Park, N., \& Peterson, C. (2005). Positive psychology progress: Empirical validation of interventions. American Psychologist, 60(5), 410-421. http://dx.doi.org/10.1037/0003-066X.60.5.410

Seligman, M. E., Rashid, T., \& Parks, A. C. (2006). Positive psychotherapy. Am Psychol, 61(8), 774788. http://dx.doi.org/10.1037/0003-066X.61.8.774 
Seligman, M. E. P. (2012). Flourish: A visionary new understanding of happiness and well-Being. Free Press.

Sheldon, K., Kashdan, T. B., \& Steger, M. F. (2011). Designing positıve psychology: taking stock and moving forward. Oxford Press.

Sin, N., \& Lyubomirsky, S. (2009). Enhancing well-being and alleviating depressive symptoms with positive psychology interventions: a practice-friendly meta-analysis. Journal of Clinical Psychology, 65(5), 467-487. https://doi.org/10.1002/jclp.20593

Smeets, E., Neff, K., Alberts, H., \& Peters, M. (2014). Meeting suffering with kindness: effects of a brief self-compassion intervention for female college students. Journal of Clinical Psychology, 70(9), 794-807. https://doi.org/ 10.1002/jclp.22076

Snyder, C. R. (2002). Hope theory: Rainbows in the mind. Psychological Inquiry, 13(4), 249-275. http://dx.doi.org/10.1207/S15327965PLI1304_01

Snyder, C. R., Rand, K. L., \& Sigmon, D. R. (2002). Hope theory: A member of the positive psychology family. In C.R. Snyder \& S. J. Lopez (Eds.), Handbook of positive psychology. Oxford University Press.

Snyder, C, R. (2005). Teaching: The lessons of hope. Journal of Social and Clinical Psychology, 24(1), 72-84. https://doi.org/10.1521/jscp.24.1.72.59169

Tarhan, S. ve Bacanlı, H. (2016). İlkokuldan üniversiteye umut kavramının tanımlanması üzerine nitel bir çalışma. Eğitimde Nitel Araştırmalar Dergisi. 4(2), 86-112. https://dergipark.org.tr/tr/pub/enad/issue/32040/354580

Vural-Yüzbaşı, D. (2018). Zihinsel engelli çocuğa sahip annelerin iyi oluşlarının başa çıkma tarzları, aile gereksinimleri ve sosyal destek değișkenleriyle modellenmesi (Yayın No. 492022) [Doktora Tezi, Ege Üniversitesi]. YÖK Tez Merkezi. https://tez.yok.gov.tr/UlusalTezMerkezi/tezSorguSonucYeni.jsp

Walsh, F. (2003). Family resilience: a framework for clinical practice. Family Process, 42(1), 1-18. https://doi.org/10.1111/j.1545-5300.2003.00001.x

Weiss, L. A., Westerhof, G. J., \& Bohlmeijer, E. T. (2016). Can we increase psychological wellbeing? the effects of interventions on psychological well-being: a meta-analysis of randomized controlled trials. Plos One, 11(6), e0158092. https://doi.org/10.1371/journal.pone.0158092

$\mathrm{Xu}, \mathrm{Y}$. (2007). Empowering culturally diverse families of young children with disabilities: the Double ABCX Model. Early Childhood Education Journal, 34(6), 431-437. http://dx.doi.org/10.1007/s10643-006-0149-0 


\section{EXTENDED ABSTRACT}

\section{Introduction}

Individuals at all levels of intellectual disability need attention from a teacher, physical or emotional support from an adult. The most important supporter of individuals with intellectual disability is their mothers. In this sense, it is important that the mother of the individual with mental disability is physically, emotionally and psychologically healthy (Vural-Yüzbaşı, 2018). In this sense, mothers who are emotionally healthy can control their emotions and behaviors, cope with difficulties and establish strong relationships (Bekhet, Johnson \& Zauszniewski, 2012). Positive psychology, which is a relatively new approach, also aims to increase well-being by addressing the strengths of individuals. The point of view of positive psychology is to catalyze a change to build the best qualities in life, rather than simply fixate on the worst things in life. As a result, it is among the aims of increasing the well-being of individuals with the study subjects they deal with and ensuring that they have a happy and healthy life (Seligman \& Csikszenmihalyi, 2000).

It is very important for both themselves and their families that families and especially mothers get out of the emotional process they are experiencing and adapt to the situation as soon as possible. In addition, it is very important to increase the positive emotions and wellbeing of parents in order to develop hope for the child's independence. When the literature that will be the subject of the research is examined, the positive psychology movement, which aims to use the potential of individuals in a functional way by addressing their strong characteristics and positive aspects, can provide explanations from many aspects of the psychological process experienced by mothers. In this sense, the aim of the study is to evaluate the psychological state of mothers of children with intellectual disability within the framework of positive psychology.

\section{Results}

As a result, parents who have a child diagnosed with intellectual disability are exposed to many difficulties and go through various stages psychologically. It is of great importance for both themselves and their families that families, and especially mothers, get out of the emotional process and adapt to the situation as soon as possible. As a matter of fact, the aim for an individual with intellectual disability is to reach the highest level of his/her potential and to enable him/her to live as an independent individual. The main task here falls on the parents. In this sense, it is very important to develop hope in the child's independence and increase the positive emotions and well-being of parents (Cooke, 2010; Seligman, 2012). In addition, by identifying the strengths that contribute to resilience in these families, interventions and support programs can be applied to strengthen these resources and thus facilitate coping in 
families who have difficulty in adapting (Ellis \& Hirsch, 2000). Strengthening the family unit in this way is important because the well-being of the family affects the well-being and harmony of its individual members, including the child with developmental disabilities (Walsh, 2003).

As seen in the results of the research, it has been observed that interventions for positive psychology increase psychological well-being, hope, self-compassion, life satisfaction and quality, and optimism in adults. In addition, when the positive psychology literature is examined, it has been seen that there are limited studies on the parents of individuals with intellectual disabilities. The aim of this study is to evaluate the psychological state of mothers of children with intellectual disability within the framework of positive psychology. In future studies, it is thought that positive psychology-based experimental and empirical research on the mothers of these families will enrich the literature. 